\title{
The Antiemetic Effect of Xiao-Ban-Xia-Tang Formula is Associated With Regulating CaM/CaMKII/ERK1/2 Signaling Pathway in Cisplatin and 1- phenylbiguanide Hydrochloride Induced Rat Pica Models
}

Lei Xia

Shandong University of Traditional Chinese Medicine

Yihong Xian

Guangdong Pharmaceutical University

Xiaodi Feng

Guangdong Pharmaceutical University

Qianqian Cheng

Guangdong Pharmaceutical University

Siqi Chen

Guangdong Pharmaceutical University

Yaqi Li

Guangdong Pharmaceutical University

Qi Meng

Shandong University of Traditional Chinese Medicine

Ke Nie ( $\nabla$ nicknk@hotmail.com )

https://orcid.org/0000-0003-4410-7662

\section{Research}

Keywords: Xiao-Ban-Xia-Tang formula, CINV, CaM/CaMKII/ERK1/2, 1-PBG, 5-HT3R, pica, cisplatin

Posted Date: July 30th, 2020

DOI: https://doi.org/10.21203/rs.3.rs-50011/v1

License: (c) (i) This work is licensed under a Creative Commons Attribution 4.0 International License.

Read Full License 


\section{Abstract}

Background: Xiao-Ban-Xia-Tang (XBXT) formula is a traditional Chinese herbal formula for treating emesis. Chemotherapy-induced nausea and vomiting (CINV) are serious side effects of chemotherapy, which was closely related to the activation of 5-hydroxytryptamine 3 receptor (5-HT3R). In this paper, the effect of XBXT on cisplatin- and 1-phenylbiguanide hydrochloride (1-PBG, a selective 5-HT3R agonist)induced pica behavior in male Wistar rats and inhibition of calmodulin/calmodulin-dependent protein kinase II/extracellular signal-regulated kinase 1/2 (CaM/CaMKII/ERK1/2) signaling pathway were investigated.

Methods: XBXT (1.6 g/kg, twice daily) was orally administered from day 1 after intraperitoneal injection of cisplatin $(6 \mathrm{mg} / \mathrm{kg})$ and 1-PBG $(25 \mathrm{mg} / \mathrm{kg})$ to day 3. Pica behavior (consumption of kaolin, a type of clay) was recorded every $24 \mathrm{~h}$. The expression and co-localization of CaM and 5-HT3R in small intestine and brain were detected by immunofluorescence. The expression of CaMKII, pCaMKII, ERK1/2, and pERK1/2 proteins were detected by Western blot.

Results: XBXT treatment significantly decreased kaolin ingestion (pica) of rats after treatment of cisplatin and 1-PBG during both $0-24 \mathrm{~h}$ (respectively, from $1.57 \mathrm{~g}$ to $0.87 \mathrm{~g}$; from $1.04 \mathrm{~g}$ to $0.11 \mathrm{~g}$ ) and $0-72 \mathrm{~h}$ (respectively, from $2.98 \mathrm{~g}$ to $1.85 \mathrm{~g}$; from $2.29 \mathrm{~g}$ to $0.35 \mathrm{~g}$ ) periods. The fluorescence expression of CaM and 5-HT3R and expression of CaMKII, pCaMKII, ERK1/2 and pERK1/2 in the small intestine and brain of cisplatin- and 1-PBG-treated rats were remarkably suppressed by XBXT.

Conclusions: The present study implies that inhibiting CaM/CaMKII/ERK1/2 signaling is an underlying mechanism of XBXT for treating CINV. These insights provide an experimental basis of XBXT for the clinical treatment of CINV.

\section{Background}

Chemotherapy-induced nausea and vomiting (CINV) is the most common, debilitating, and fearing side effects among cancer patients receiving chemotherapeutic drugs. Lack of proper antiemetic prophylaxis, about $90 \%$ of patients experience CINV after receiving highly emetogenic chemotherapies (HEC), which seriously affects their quality of life [1-3]. Moreover, severe nausea and vomiting may lead to a reduction in adherence to the anti-cancer regimen, thus, the prevention and management of CINV are a priority in the oncology setting [4]. Researchers have elucidated some of the mechanisms of CINV over the past decades. Cytotoxic chemotherapeutic drugs stimulate enterochromaffin cells of the gastrointestinal (GI) tract and area postrema of the brain to release neurotransmitters, which subsequently cause nausea and vomiting by activating relative receptors, including 5-HT3R, neurokinin-1 (NK1) receptor, dopamine receptor, and cholecystokinin-1 receptor $[4,5]$. Some antiemetic drugs targeting on these receptors have been developed, such as ondansetron (one of the 5-HT3R antagonists), netupitant (one of the NK1 receptor antagonists), and metoclopramide (one of the dopamine D2 antagonists). Especially, the clinical utilization of 5-HT3R antagonists leads to a significant improvement in preventing CINV in the first $24 \mathrm{~h}$ 
post chemotherapy [6]. Besides, it has been demonstrated the significant improvement of NEPA in the control of CINV in the period $24 \mathrm{~h}$ to $120 \mathrm{~h}$ post chemotherapy, which is the first antiemetic combination product comprising of the new NK1 receptor antagonist and the 5-HT3R antagonist (netupitant plus palonosetron) [7]. There is great success in the treatment of CINV. But preclinical and clinical trials have shown that some of the 5-HT3R antagonists, main antiemetic agents, caused electrocardiogram interval changes, in particular, QTC prolongation [7]. What's more, the cost of treatment and prevention of CINV are expensive $[8,9]$. Therefore, it is necessary to develop some new treatments for treating CINV.

Xiao-Ban-Xia-Tang (XBXT) is a traditional Chinese herbal formula that is composed of the roots of ginger (Zingiber officinale Rosc.) and the tubers of pinellia (Pinellia ternata (Thunb.) Breit.) in a weight ratio of 1: 2, which had been used for treating emesis in China for nearly 2000 years. Cisplatin is used for treating various types of cancer, which is usually accompanied by severe side effects, such as nausea and emesis [10]. Mink study has shown that XBXT ameliorated cisplatin-induced acute and delayed emesis, which is associated with its inhibited effects on central or peripheral neurokinin-1 receptor levels [11]. Rodents cannot vomit, but pica (consumption of non-nutritive substances such as kaolin, china clay) in rats is analogous to emesis [12]. Rat studies have shown that XBXT had a therapeutic effect on cisplatininduced pica behavior, which is possibly related to inhibit the activation of NLRP3 inflammasome and the increased level of 5-HT and expression of 5-HT3 receptor [11, 13, 14]. Ginger is a key component of XBXT, which is believed to play an important role in treating nausea and emesis. It is reported that ginger extract can counteract CINV in a randomized, double-blind, placebo-controlled, multicenter study [15]. Heba Abdel-Aziz et al considered that different extracts of ginger, such as [6]-, [8]-, [10]-gingerol and [6]-shogaol acted on the 5-HT3 receptor ion-channel complex and inhibited 5-HT3 receptor function to exert their antiemetic effect $[16,17]$. In addition, it is reported that the volatile oil from ginger and distinct compounds such as terpinolene, b-pinene, and a-phellandrene possess an antispasmodic effect at the rat ileum associating their functions on 5-HT3 receptor channel system [18]. Studies also have found that ginger and its pungent constituents non-competitively inhibited activation of human recombinant and native 5HT3 receptors of enteric neurons as well as inhibited serotonin currents on visceral afferent neurons [19, 20]. Gingerol, the main pungent constituents of ginger [21], is effective for inhibiting cisplatin-induced acute and delayed emesis in rat pica model and mink because of its regulation of central and peripheral $5-\mathrm{HT}, \mathrm{SP}$, and DA systems [22, 23]. [6]-gingerol is the most bioactive compound of gingerol [21], which can significantly improve the overall complete response (CR) rate in CINV as well as appetite and quality of life in cancer patients and can also ameliorate the alteration of gut microbiome induced by cisplatin in rats $[24,25]$. Additionally, study has shown that [6]-shogaol had a direct activation of vagal afferent Cfiber peripheral gastrointestinal endings and thereafter desensitized this activation, which shows potential anti-emetic effects [26]. As described above, XBXT exhibited the therapeutic effect of CINV, which is associated with several mechanisms. Among them, inhibiting activation of 5-HT3R is one of the mechanisms of XBXT for the prevention and treatment of CINV. Given the central role of 5-HT3 receptor in the pathways leading to CINV, the interaction of XBXT and central and peripheral emetic signaling components downstream of 5-HT3 receptor activation need to be further explored. 
Serotonergic receptors are G-protein-coupled receptors excepted the 5-HT3 receptor that is a cysteine-loop ligand-gated ion channel receptor and exists throughout the brainstem dorsal vagal complex and $\mathrm{GI}$ tract [27]. As an ion channel that is permeable to the cations $\left(\mathrm{Na}^{+}, \mathrm{K}^{+}, \mathrm{Ca}^{2+}\right)$, the $5-\mathrm{HT} 3$ receptor mediates fast depolarizing responses in pre- and post-synaptic neurons [28]. It is reported that 5-HT3R-mediated vomiting is associated with $\mathrm{Ca}^{2+}$-CaMKII-ERK1/2 cascade signaling $[29,30]$. To be specific, the activation of 5-HT3R induces extracellular $\mathrm{Ca}^{2+}$ influx, which results in the activation of $\mathrm{CaM}$, CaMKIla and ERK1/2 proteins, eventually leads to the occurrence of CINV [31]. Additionally, studies have found that cisplatin caused dysregulation of calcium $\left(\mathrm{Ca}^{2+}\right)$ homeostasis and chemotherapeutics caused vomiting via $\mathrm{Ca}^{2+}$ dependent release of multiple neurotransmitters $[5,32]$. What's more, exposure of dorsal root ganglion neurons to cisplatin for 24 - $28 \mathrm{~h}$ in vitro significantly increased CaMKII-mediated $\mathrm{I}_{\mathrm{Ca}(\mathrm{v})}$ current density [32, 33]. Study also has found that cisplatin elevated the phosphorylation of ERK1/2 [34]. It seems that chemotherapeutics caused the activation of 5-HT3R and subsequently results in the activation of $\mathrm{CaM} / \mathrm{CaMKII/} \mathrm{ERK1/2} \mathrm{signaling} \mathrm{pathway,} \mathrm{which} \mathrm{eventually} \mathrm{leads} \mathrm{to} \mathrm{the} \mathrm{occurrence} \mathrm{of} \mathrm{CINV.} \mathrm{Previous}$ studies indicated that this signaling pathway triggered by the activation of 5-HT3R can be regarded as a therapeutic target for treating CINV. Thus, we hypothesize that inhibiting CaM/CaMKII/ERK $1 / 2$ signaling triggered by the activation of 5-HT3R could be one of the underlying mechanisms of XBXT for the prevention and treatment of CINV. 1-PBG is a kind of selective 5-HT3R agonist, which can cause vomiting in the cat [35]. We established both cisplatin-induced and 1-PBG-induced rat pica models to investigate the relationship between XBXT and CaM/CaMKII/ERK1/2 signaling pathway triggered by the activation of 5-HT3R. And ondansetron, a 5-HT3R antagonist, was used as a positive control, which is also widely used for treating CINV.

In the present study, we investigated the effect of XBXT in cisplatin- and 1-PBG-induced rat pica models and characterized the potential mechanisms of the antiemetic effect of XBXT against CINV by focusing on regulating $\mathrm{CaM} / \mathrm{CaMKII/ERK1/2}$ signaling pathway, which provides an experimental basis of XBXT for the clinical treatment of CINV

\section{Methods}

\section{Drugs and reagents.}

Ginger and pinellia were bought in September 2019. The roots of Ginger were produced in Laiwu City, Shandong Province, China, voucher specimen no. J7201. The tubers of pinellia were produced in Xihe County, Gansu Province, China, voucher specimen no. J7654. Both of them were authenticated by Professor Jizhu Liu (Guangdong Pharmaceutical University, Guangzhou, China). Pure standards of [6]gingerol and [6]-shogaol were from Manst Biotechnology Co., Ltd., Chengdu, China. Pure standards of ephedrine and succinic acid were from China Institute of Food and Drug Verification. Ondansetron and cisplatin were from Qilu Pharmaceutical Company, China. Kaolin powder was from China Pharmaceutical Chemical Reagents Company, China. 1-PBG was from Sigma-Aldrich Company, USA.

\section{Preparation of kaolin pellets and XBXT formula.}


Kaolin pellets were prepared according to our previously reported method (25). The roots of ginger $200 \mathrm{~g}$ and the tubers of pinellia $400 \mathrm{~g}$ were soaked in $4800 \mathrm{~mL}$ distilled water overnight and boiled for $1.5 \mathrm{~h}$ at $100^{\circ} \mathrm{C}$. After filtration, the dregs were boiled in distilled water one more time following the same procedure. The extract from two soaking and filtering was lyophilized to form a dried powder.

\section{UPLC-Q-Orbitrap MS analysis of XBXT.}

XBXT samples were analyzed by UPLC-Q-Orbitrap MS using ThermoFisher Scientific (TF, Dreieich, Germany) Dionex UltiMate 3000. The separation was performed on a RP-C18 column (150 mm $\times 2.1 \mathrm{~mm}$, $1.8 \mu \mathrm{m}$, Welch), operating at a flow rate of $0.3 \mathrm{~mL} / \mathrm{min}$ throughout the gradient. The column temperature was $35^{\circ} \mathrm{C}$, and the injection volume was $10 \mu \mathrm{L}$, Eluent $A$ was $0.1 \%$ formic acid in water, and eluent $B$ was $0.1 \%$ formic acid in acetonitrile methanol. Separation was conducted under the following conditions: 0 - 1 $\min , 2 \%$ B; 1 - 5 min, 20\% B; 5 - 10 min, 50\% B; 10 - 15 min, 80\% B; 15 - 20 min, 95\% B; 20 - 25 min, 95\% B; $25-26 \mathrm{~min}, 2 \%$ B. $26-30 \mathrm{~min}, 2 \%$ B. For the MS analysis, ESI source conditions were set as following: sheath gas flow rate as $40 \mathrm{Arb}$, aux gas flow rate as $15 \mathrm{Arb}$, capillary temperature $300^{\circ} \mathrm{C}$, full mass resolution as $70000, \mathrm{MS} / \mathrm{MS}$ resolution as 17500 , spray voltage as $3.8 \mathrm{kV}$ (positive). The auxiliary gas heater temperature and capillary temperature were both controlled to $350^{\circ} \mathrm{C}$. Nitrogen was used for spraying stabilization and damping gas in the Ctrap. The analysis was performed in the full scan mode with a positive ion swing. The resolution was 70,000 (full mass). The full MS scan ranges were set from 150 to $2000 \mathrm{~m} / \mathrm{z}$. All of the collected data in the profile were acquired and processed using Thermo Xcalibur 3.0 software (Thermo Scientific, USA). Results of UPLC-Q-Orbitrap MS analysis of XBXT formula were shown in Figure S1.

\section{Animals and treatment.}

56 male Wistar rats (200 - $230 \mathrm{~g}$ ) were purchased from Jinan Pengyue Experimental Animal Breeding Co., Ltd, China) and housed in environmental conditions (temperature: $23 \pm 2{ }^{\circ} \mathrm{C}$, the relative humidity: $40 \%$ $60 \%$, the alternating time of day and night: $12 \mathrm{~h} / 12 \mathrm{~h}$ ). The rats were free to access standard diet and water. All the animal experiments were approved by the Committee on Laboratory Animal Care and Use of Guangdong Pharmaceutical University (Guangzhou, China). After adaptive feeding for 3 days, the rats were randomly divided into 7 groups $(n=8)$ : group 1 (normal control group (Control)); group 2 (cisplatin model group (C-Model)); group 3 (ondansetron + cisplatin model group (C-Ondansetron); group 4 (XBXT + cisplatin (C-XBXT)); group 5 (1-PBG model group (P-Model); group 6 (ondansetron + 1-PBG model group (P-Ondansetron); group 7 (XBXT + 1-PBG model group (P-XBXT).

Kaolin pellets were added before drug administration in 3 days to make the rats familiar with the presence of kaolin pellets. Those rats that still took in large amounts of kaolin pellets on the third day were excluded. On the day of drug administration, the rats of C-XBXT and P-XBXT were given XBXT (1.6 $\mathrm{g} / \mathrm{kg}$ [body weight (B.W.)]) by gavage respectively. The rats of C-Ondansetron and P-Ondansetron were given ondansetron (1.3 mg/kg [B.W.]) by gavage respectively. The rats of Control, C-Model and P-Model were given distilled water ( $10 \mathrm{~g} / \mathrm{kg}$ [B.W.]) by gavage respectively. The above dosage was given by gavage every $12 \mathrm{~h}$ (8: $00 \mathrm{AM}, 20: 00 \mathrm{PM}$ ) until the end of the experiment for a total of 7 times. After $1 \mathrm{~h}$, 
the rats of C-Model, C-Ondansetron and C-XBXT were injected with cisplatin intraperitoneally (i.p.) at the concentration of $6 \mathrm{mg} / \mathrm{kg}$ (B.W.) and the rats of P-Model, P-Ondansetron and P-XBXT were injected with 1-PBG intraperitoneally at the concentration of $25 \mathrm{mg} / \mathrm{kg}$ (B.W.), while the rats of Control were injected with saline of equal volume intraperitoneally.

During the experiment, the spirit, activity, fur, appetite and stool of the rats were observed every day. The kaolin intake of rats was measured every $24 \mathrm{~h}$. All animals were anesthetized by intraperitoneal injection of $2 \%$ nembutal ( $45 \mathrm{mg} / \mathrm{kg} \mathrm{B.W}$.) before sacrifice.

\section{Immunofluorescence.}

The co-localization of CaM and 5-HT3R in small intestine and brain were detected by immunofluorescence. The brain and small intestine tissues were embedded in paraffin and sliced into 4 $\mu \mathrm{m}$ sections. The slides were blocked with goat serum for $30 \mathrm{~min}$ at room temperature and incubated overnight at $4^{\circ} \mathrm{C}$ with the following antibodies: rabbit anti-CaM (1: 2000, Abcam, \#ab45689); rabbit anti5HT3R (1: 2000, Abcam, \#ab13897). After that, the slices were incubated with corresponding Fluorconjugated secondary antibody (1: 600, Servicebio, \#GB21303) at room temperature for $1 \mathrm{~h}$. Nuclei of cells were stained with DAPI. The expression of protein in cells was observed by fluorescence microscope (Nikon, Japan).

\section{Western blot analysis.}

Total proteins of the brain and intestinal tissue were extracted using RIPA lysis buffer (P1003B, Beyotime, China), which containing protease and phosphatase inhibitor. The protein concentration was detected with the BCA protein quantitative kit (P0011, Beyotime, China). Proteins were electrophoresed by SDSPAGE gel and transferred to a PVDF membrane. After blocked in $5 \%$ non-fat dry milk for $1 \mathrm{~h}$ at room temperature, the membrane were incubated separately at $4{ }^{\circ} \mathrm{C}$ overnight with the following antibodies: CaMKII(1: 2000, Abcam, \#ab22609), p-CaMKII (1: 2000, Abcam, \#ab171095), ERK (1: 2000, CST, \#9107S), p-ERK (1: 2000, CST, \#4370S). Then membranes were washed and incubated for $1 \mathrm{~h}$ at room temperature with an anti-rabbit or anti-mouse secondary antibody. Immunoreactive complexes were incubated in ECL kit and exposed for film using BioSpectrum Imaging System (UVP, Upland, CA). The gray value of the protein was measured with Image-J software.

\section{Statistical analysis.}

Graphpad Prism 6 statistical software (San Diego, CA, USA) was used for data analysis. All data were expressed as mean \pm SEM. Two-way analysis of variance (ANOVA) was used to compare differences between multiple groups, and the results were analyzed by Tukey's multiple comparisons test. $P$ value less than 0.05 was considered to be significant.

\section{Results}


As showed in Fig. 1, the kaolin intake of rats of the C-Model was significantly increased during 0 - $24 \mathrm{~h}, 0$ $48 \mathrm{~h}$ and $0-72 \mathrm{~h}$ periods, compared with the rats of Control $(P<0.001)$. The kaolin intake of rats of the CXBXT was significantly decreased during $0-24 \mathrm{~h}(P<0.05)$ and $0-72 \mathrm{~h}(P<0.001)$ periods, compared with the rats of $\mathrm{C}$-Model. The kaolin intake of rats of the $\mathrm{C}$-Ondansetron was significantly decreased during 0 - $24 \mathrm{~h}, 0-48 \mathrm{~h}$ and $0-72 \mathrm{~h}(P<0.001)$ periods, compared with the rats of C-Model. The kaolin intake of rats of the P-Model was significantly increased during $0-24 \mathrm{~h}, 0-48 \mathrm{~h}$ and $0-72 \mathrm{~h}$ periods, compared with the rats of Control $(P<0.001)$. The kaolin intake of rats of the P-XBXT and the POndansetron was significantly decreased during $0-24 \mathrm{~h}$ (both $P<0.001), 0-48 \mathrm{~h}(P<0.001, P<0.01)$ and $0-72 \mathrm{~h}$ (both $P<0.001$ ) periods, compared with the rats of P-Model.

\section{Effect of XBXT formula on co-localization of CaM and 5-HT3R in small intestine and brain.}

The co-localization of CaM and 5-HT3R in small intestine and brain were detected by immunofluorescence. The expression of 5-HT3R protein was red, the expression of CaM protein was green, and the co-locational tissue of CaM and 5-HT3R was yellow. Compared with the Control, the colocalization of 5-HT3R and CaM in the small intestine and brain tissues of rats of C-Model were increased $(P<0.05)$. As showed in Fig. 2 and Fig. 3, after treating with ondansetron and XBXT formula, the colocalization of 5-HT3R and CaM in the small intestine and brain tissues were significantly decreased $(P<$ 0.05). Similarly, compared with the Control, the co-localization of 5-HT3R and CaM in the small intestine and brain tissues of rats of P-Model were increased $(P<0.05)$. After treating with ondansetron and XBXT formula, the co-localization of 5-HT3R and CaM in the small intestine and brain tissues were significantly decreased $(P<0.05)$

\section{Effect of XBXT formula on the expression of CaMKII protein and the phosphorylation of CaMKII protein in small intestine and brain.}

Western Blot was used to detect the expression levels of CaMKII and pCaMKII proteins. Compared with the Control, the expression of CaMKII and the phosphorylation of CaMKII proteins in the small intestine and brain tissues of rats of C-Model were increased $(P<0.05)$. After treating with ondansetron and XBXT formula, the expression of CaMKII and the phosphorylation of CaMKII proteins in the small intestine and brain tissues were decreased (Fig. 4). Similarly, compared with the Control, the expression of CaMKII and the phosphorylation of CaMKII proteins in the small intestine and brain tissues of rats of P-Model were increased $(P<0.05)$. After treating with ondansetron and XBXT formula, the expression of CaMKII and the phosphorylation of CaMKII proteins in the small intestine and brain tissues were decreased $(P<0.01)$ (Fig. 5).

\section{Effect of XBXT formula on the expression of ERK1/2 protein and the phosphorylation of ERK1/2 protein in small intestine and brain.}

Western Blot was used to detect the expression of ERK1/2 protein and the phosphorylation of ERK $1 / 2$ protein. The expression of ERK $1 / 2$ and the phosphorylation of ERK $1 / 2$ protein in the small intestine and brain tissues of the $\mathrm{C}$-Model was increased compared with the Control $(P<0.05)$. After treating with 
ondansetron and XBXT formula, the expression of ERK1/2 protein and the phosphorylation of ERK1/2 protein in the small intestine and brain tissues was decreased (Fig. 6). Similarly, the expression of ERK1/2 and the phosphorylation of ERK1/2 protein in the small intestine and brain tissues of the P-Model was increased compared with the Control $(P<0.05)$. After treating with ondansetron and XBXT formula, the expression of ERK $1 / 2$ protein and the phosphorylation of ERK $1 / 2$ protein in the small intestine and brain tissues was decreased $(P<0.001)$ (Fig. 7).

\section{Discussion}

The development of antiemetics has substantially changed the landscape for treating CINV [36]. In consideration of the central role of 5-HT3 receptor in the pathways leading to CINV, the 5-HT3R antagonists are believed to play the most important role for treating CINV [37]. Especially, the development of palonosetron, a second generation of 5-HT3 receptor antagonists, exhibited superior effects in phase III clinical trials for the prevention of acute, delayed, and overall CINV comparing with other 5-HT3R antagonists because of its more potent binding affinity and longer half-life [38]. It is said that it can also affect the cross-talk between NK-1 and 5-HT3 receptors signaling pathway, which provides a further explanation for the demonstrated efficacy of this drug in controlling delayed CINV [37]. The occurrence of CINV is associated with several systems, thus, a single antiemetic agent has a limitation for treating CINV. Using a combination of antiemetic drugs (such as NEPA) is a potent strategy for treating CINV, but it also puts a heavy financial burden on the patient [39]. Traditional Chinese medicines (TCMs) contain a variety of active ingredients, which could work on different target mildly. What's more, some TCMs are also food materials, such as ginger, the key antiemetic agent of XBXT, which is safer and cost-effective.

XBXT has been used for treating emesis in a long history in China. In present study, we found that XBXT exhibited an ameliorative effect on both cisplatin-induced and 1-PBG-induced emesis in rats, which is consistent with previous research $[11,14]$. Some underlying mechanisms of XBXT for the prevention and treatment of CINV have been explored. Our previous studies have found that cisplatin caused gastrointestinal inflammation and altered gut microbiome in rats, while XBXT and [6]-gingerol ameliorated such situations $[13,25]$. Besides, study has revealed that serotonin and its receptors, mainly 5-HT3 receptor, is overexpressed in inflammatory bowel disease (IBD) and 5-HT3 receptor antagonists have anti-inflammatory properties in certain inflammatory conditions such as colitis [40]. Additionally, 5HT3R-related pathway stands on the leading role in the occurrence of CINV. Thus, XBXT exhibited an inhibited effect on 5-HT3R. In this paper, we investigated the effects of XBXT on central and peripheral emetic signaling components downstream of 5-HT3R activation.

Weixia Zhong et al found that chemotherapeutics caused vomiting by activating 5-HT3 receptor and its downstream signaling pathway, $\mathrm{Ca}^{2+} / \mathrm{CaMKII/ERK1/2}$ signaling pathway, while inhibitors of CaMKII (KN93) and ERK1/2 (PD98059) dose-dependently suppressed emesis [31]. And Nissar A. Darmani et al found that activation of L-type calcium channels (LTCC) also caused vomiting, whereas nifedipine-like drugs (LTCC antagonists) not only provide broad-spectrum antiemetic activity but also potentiate the 
antiemetic efficacy of well-established antiemetics such as palonosetron [29, 41]. Study has found that cisplatin caused dysregulation of calcium homeostasis [32]. Intracellular receptor CaM triggers a variety of downstream processes and pathways after binding with calcium [42]. CaMKII mediated ERK1/2 activation in response to $\mathrm{Ca}^{2+}$-mobilizing stimuli [43]. Study has found that the toxicity of cisplatin was associated with the activation of ERK1/2 protein $[44,45]$. These studies provide potent evidence that $\mathrm{Ca}^{2+} /$ CaMKII/ERK1/2 signaling pathway is a therapeutic target for treating CINV. In the present study, we found that XBXT inhibited CaM/CaMKII/ERK1/2 signaling pathway, which maybe its effective mechanism for treating CINV.

The relationship between CINV and CaM/CaMKII/ERK1/2 signaling pathway provides new insights into the pathophysiology of $\mathrm{CINV} . \mathrm{Ca}^{2+}$ is an important second messenger that participates in various physiological and pathological activities. For example, study has found that inflammation and NLRP3 inflammasome activation initiated by $\mathrm{Ca}^{2+} / \mathrm{CaMKII \delta}$ signaling in cardiomyocytes are essential for adverse cardiac remodeling [46]. What's more, study has found that cisplatin induced the accumulation of calcium ions in inner hair cells and impaired vesicles cycling [47]. Additionally, study has found that granisetron, a 5-HT3R antagonist, rectified calcium dyshomeostasis in TgSwDI mice brains by restoring CaMKII/cAMP-response element binding protein pathway, which was associated with cognitive improvement [48]. Malik Bisserier et al found that Carabin, a protein expressed in cardiomyocytes, protects against cardiac hypertrophy partly by blocking $\mathrm{Ca}^{2+} / \mathrm{CaMKII}$ Signaling [47]. It is obvious that $\mathrm{Ca}^{2+}$ and its relative signaling pathways can be regarded as therapeutic targets for so many diseases. Additionally, it is considered that CINV is mainly triggered by the activation of 5-HT3R, which subsequently activates $\mathrm{Ca}^{2+}$ / CaMKII/ERK1/2 signaling pathway. In our present study, we considered that XBXT formula inhibits CINV partly by inhibiting CaM/CaMKII/ERK1/2 signaling pathway.

XBXT is composed of ginger and pinellia, which are cost-effective and easy to obtain from nature. Especially, ginger is a key component of XBXT, which have been used for treating CINV in clinic [15]. Pinellia, another key component of XBXT, is used for the treatment of cough, phlegm, and vomiting in pregnant women [49]. TCMs have been widely used in treating CINV in China. And pinellia is one of the most frequently used herbs for treating CINV in China [50]. Based on the theory of TCMs, the combination of ginger and pinellia exhibits a stronger antiemetic effect. Ginger have been used for treating CINV in clinic, and the pungent constituents of ginger, such as gingerol and shogaol, are believed to play the most important role.

$\mathrm{Ca}^{2+}$ plays an important role in stimulus-response reactions of cells as a second messenger, which involves in several elements, such as LTCC, mitochondria, transient receptor potential channel and ryanodine receptor [51-54]. In present study, we focused on the effects of XBXT on CaM/CaMKII/ERK1/2 signaling pathway. But whether XBXT has effects on LTCC, mitochondria, transient receptor potential channel and ryanodine receptor remain unclear, which should be further explored.

\section{Conclusion}


The present study implies that inhibiting CaM/CaMKII/ERK1/2 signaling could be one of the underlying mechanisms of XBXT for the treating CINV. These insights provide an experimental basis of XBXT for the clinical treatment of CINV.

\section{Abbreviations}

XBXT: Xiao-Ban-Xia-Tang formula; CINV: Chemotherapy-induced nausea and vomiting; 5-HT3R: 5hydroxytryptamine 3 receptor; 1-PBG: 1-phenylbiguanide hydrochloride; CaM: calmodulin; CaMKII: calmodulin-dependent protein kinase II; ERK1/2: extracellular signal-regulated kinase 1/2; HEC: highly emetogenic chemotherapies; GI: gastrointestinal; NK1: neurokinin-1; TCMs: traditional Chinese medicines; IBD: inflammatory bowel disease; LTCC: L-type calcium channels;

\section{Declarations}

\section{Acknowledgements}

Not applicable

\section{Authors' contributions}

$\mathrm{KN}$ designed the research. $\mathrm{XL}, \mathrm{XY}, \mathrm{FX}, \mathrm{CQ}, \mathrm{CS}, \mathrm{LY}$ and $\mathrm{MQ}$ conducted the experiments. $\mathrm{XL}$ and $\mathrm{XY}$ wrote the manuscript. FX, CQ, CS, LY, MQ and NK revised the manuscript. All authors read and approved the final manuscript.

\section{Availability of data and materials}

Not applicable.

\section{Ethics approval and consent to participate}

The study was established according to the ethical guidelines and approved by the Committee on Laboratory Animal Care and Use of Guangdong Pharmaceutical University (Guangzhou, China).

\section{Consent for publication}

We declare that the Publisher has the Author's permission to publish the relevant contribution.

\section{Competing interests}

The authors declare that there is no conflict of interest regarding the publication of this paper.

\section{Funding Statement}

This work was supported by the National Natural Science Foundation of China (No. 81673779). 


\section{References}

1. Fernandez-Ortega P, Caloto MT, Chirveches E, Marquilles R, Francisco JS, Quesada A, et al. Chemotherapy-induced nausea and vomiting in clinical practice: impact on patients' quality of life. Support Care Cancer. 2012;20:3141-8.

2. Ballatori E, Roila F, Ruggeri B, Betti M, Sarti S, Soru G, et al. The impact of chemotherapy-induced nausea and vomiting on health-related quality of life. Support Care Cancer. 2007;15:179-85.

3. Bloechl-Daum B, Deuson RR, Mavros P, Hansen M, Herrstedt J. Delayed nausea and vomiting continue to reduce patients' quality of life after highly and moderately emetogenic chemotherapy despite antiemetic treatment. J Clin Oncol. 2006;24:4472-8.

4. Navari RM, Aapro M. Antiemetic Prophylaxis for Chemotherapy-Induced Nausea and Vomiting. N Engl J Med. 2016;374:1356-67.

5. Hesketh PJ. Chemotherapy-induced nausea and vomiting. N Engl J Med. 2008;358:2482-94.

6. Navari RM. 5-HT3 receptors as important mediators of nausea and vomiting due to chemotherapy. Biochim Biophys Acta. 2015;1848:2738-46.

7. Karin J, Franziska J, Matti A. Recent developments in the prevention of chemotherapy-induced nausea and vomiting (CINV) A comprehensive review. Ann Oncol. 2015;26:1081-90.

8. Tina Shih YC, Xu Y, Elting LS. Costs of uncontrolled chemotherapy-induced nausea and vomiting among working-age cancer patients receiving highly or moderately emetogenic chemotherapy. Cancer. 2007;110:678-85.

9. Ballatori E, Roila F, Ruggeri B, Porrozzi S, lannopollo M, Soru G, et al. The cost of chemotherapyinduced nausea and vomiting in Italy. Support Care Cancer. 2007;15:31-8.

10. Ranganath P, Einhorn L, Albany C. Management of Chemotherapy Induced Nausea and Vomiting in Patients on Multiday Cisplatin Based Combination Chemotherapy. Biomed Res Int. 2015;2015:943618.

11. Qian Q, Chen W, Yue W, Yang Z, Liu Z, Qian W. Antiemetic effect of Xiao-Ban-Xia-Tang, a Chinese medicinal herb recipe, on cisplatin-induced acute and delayed emesis in minks. J Ethnopharmacol. 2010;128:590-3.

12. Takeda N, Hasegawa S, Morita M, Matsunaga T. Pica in rats is analogous to emesis: an animal model in emesis research. Pharmacol Biochem Behav. 1993;45:817-21.

13. Meng Q, Cheng Q, Feng X, Chen S, Li Y, Zhang G, et al. The Antiemetic Effect of Xiao-Ban-Xia-Tang Formula against Cisplatin-Induced Emesis is Mediated through Inhibition of NLRP3 Inflammasome Activation in a Rat Pica Model. Evid Based Complement Alternat Med. 2020;2020:5497078.

14. Qian Q, Chen W, Guo C, Wu W, Qian W, Li S. Xiao-Ban-Xia-Tang inhibits cisplatin-induced pica by down regulating obestatin in rats. J Ethnopharmacol. 2011;135:186-93.

15. Bossi P, Cortinovis D, Fatigoni S, Cossu Rocca M, Fabi A, Seminara P, et al. A randomized, doubleblind, placebo-controlled, multicenter study of a ginger extract in the management of chemotherapy- 
induced nausea and vomiting (CINV) in patients receiving high-dose cisplatin. Ann Oncol. 2017;28:2547-51.

16. Abdel-Aziz H, Nahrstedt A, Petereit F, Windeck T, Ploch M, Verspohl EJ. 5-HT3 receptor blocking activity of arylalkanes isolated from the rhizome of Zingiber officinale. Planta Med. 2005;71:609-16.

17. Abdel-Aziz H, Windeck T, Ploch M, Verspohl EJ. Mode of action of gingerols and shogaols on 5-HT3 receptors: binding studies, cation uptake by the receptor channel and contraction of isolated guineapig ileum. Eur J Pharmacol. 2006;530:136-43.

18. Riyazi A, Hensel A, Bauer K, Geissler N, Schaaf S, Verspohl EJ. The effect of the volatile oil from ginger rhizomes (Zingiber officinale), its fractions and isolated compounds on the 5-HT3 receptor complex and the serotoninergic system of the rat ileum. Planta Med. 2007;73:355-62.

19. Walstab J, Kruger D, Stark T, Hofmann T, Demir IE, Ceyhan GO, et al. Ginger and its pungent constituents non-competitively inhibit activation of human recombinant and native 5-HT3 receptors of enteric neurons. Neurogastroenterol Motil. 2013;25:439-47, e302.

20. Jin Z, Lee G, Kim S, Park CS, Park YS, Jin YH. Ginger and its pungent constituents non-competitively inhibit serotonin currents on visceral afferent neurons. Korean J Physiol Pharmacol. 2014;18:149-53.

21. Liu Y, Liu J, Zhang Y. Research Progress on Chemical Constituents of Zingiber officinale Roscoe. Biomed Res Int. 2019;2019:5370823.

22. Tian L, Qian W, Qian Q, Zhang W, Cai X. Gingerol inhibits cisplatin-induced acute and delayed emesis in rats and minks by regulating the central and peripheral 5-HT, SP, and DA systems. J Nat Med. 2020;74:353-70.

23. Qian QH, Yue W, Wang YX, Yang ZH, Liu ZT, Chen WH. Gingerol inhibits cisplatin-induced vomiting by down regulating 5-hydroxytryptamine, dopamine and substance $\mathrm{P}$ expression in minks. Arch Pharm Res. 2009;32:565-73.

24. Konmun J, Danwilai K, Ngamphaiboon N, Sripanidkulchai B, Sookprasert A, Subongkot S. A phase II randomized double-blind placebo-controlled study of 6-gingerol as an anti-emetic in solid tumor patients receiving moderately to highly emetogenic chemotherapy. Med Oncol. 2017;34:69.

25. Feng X, Cheng Q, Meng Q, Yang Y, Nie K. Effects of ondansetron and [6]-gingerol on pica and gut microbiota in rats treated with cisplatin. Drug Des Devel Ther. 2019;13:2633-41.

26. Huang Y, Patil MJ, Yu M, Liptak P, Undem BJ, Dong X, et al. Effects of ginger constituent 6-shogaol on gastroesophageal vagal afferent C-fibers. Neurogastroenterol Motil. 2019;31:e13585.

27. Gothert M, Bonisch H, Malinowska B, Schlicker E. Serotonin discovery and stepwise disclosure of 5HT receptor complexity over four decades. Part II. Some contributions of Manfred Gothert. Pharmacol Rep. 2020;72:271-84.

28. Machu TK. Therapeutics of 5-HT3 receptor antagonists: current uses and future directions. Pharmacol Ther. 2011;130:338-47.

29. Hutchinson TE, Zhong W, Chebolu S, Wilson SM, Darmani NA. L-type calcium channels contribute to 5-HT3-receptor-evoked CaMKIlalpha and ERK activation and induction of emesis in the least shrew (Cryptotis parva). Eur J Pharmacol. 2015;755:110-8. 
30. Zhong W, Picca AJ, Lee AS, Darmani NA. Ca(2+) signaling and emesis: Recent progress and new perspectives. Auton Neurosci. 2017;202:18-27.

31. Zhong W, Hutchinson TE, Chebolu S, Darmani NA. Serotonin 5-HT3 receptor-mediated vomiting occurs via the activation of $\mathrm{Ca} 2+/ \mathrm{CaMKII-dependent} \mathrm{ERK1/2} \mathrm{signaling} \mathrm{in} \mathrm{the} \mathrm{least} \mathrm{shrew} \mathrm{(Cryptotis}$ parva). PLoS One. 2014;9:e104718.

32. Conte E, Camerino GM, Mele A, De Bellis M, Pierno S, Rana F, et al. Growth hormone secretagogues prevent dysregulation of skeletal muscle calcium homeostasis in a rat model of cisplatin-induced cachexia. J Cachexia Sarcopenia Muscle. 2017;8:386-404.

33. English K, Shepherd A, Uzor NE, Trinh R, Kavelaars A, Heijnen CJ. Astrocytes rescue neuronal health after cisplatin treatment through mitochondrial transfer. Acta Neuropathol Commun. 2020;8:36.

34. Wang Z, Sun W, Sun X, Wang Y, Zhou M. Kaempferol ameliorates Cisplatin induced nephrotoxicity by modulating oxidative stress, inflammation and apoptosis via ERK and NF-kappaB pathways. AMB Express. 2020;10:58.

35. Miller AD, Nonaka S. Mechanisms of vomiting induced by serotonin-3 receptor agonists in the cat: effect of vagotomy, splanchnicectomy or area postrema lesion. J Pharmacol Exp Ther. 1992;260:509-17.

36. Schwartzberg L, Roeland E, Andric Z, Kowalski D, Radic J, Voisin D, et al. Phase III safety study of intravenous NEPA: a novel fixed antiemetic combination of fosnetupitant and palonosetron in patients receiving highly emetogenic chemotherapy. Ann Oncol. 2018;29:1535-40.

37. Schwartzberg LS, Jacobs P, Matsouka P, Azevedo W, Pinto A. The role of second-generation 5-HT3 receptor antagonists in managing chemotherapy-induced nausea and vomiting in hematological malignancies. Crit Rev Oncol Hematol. 2012;83:59-70.

38. Rojas C, Stathis M, Thomas AG, Massuda EB, Alt J, Zhang J, et al. Palonosetron exhibits unique molecular interactions with the 5-HT3 receptor. Anesth Analg. 2008;107:469-78.

39. Botteman M, Nickel K, Corman S, Turini M, Binder G. Cost-effectiveness of a fixed combination of netupitant and palonosetron (NEPA) relative to aprepitant plus granisetron (APR + GRAN) for prophylaxis of chemotherapy-induced nausea and vomiting (CINV): a trial-based analysis. Support Care Cancer. 2020;28:857-66.

40. Amini-Khoei H, Momeny M, Abdollahi A, Dehpour AR, Amiri S, Haj-Mirzaian A, et al. Tropisetron suppresses colitis-associated cancer in a mouse model in the remission stage. Int Immunopharmacol. 2016;36:9-16.

41. Darmani NA, Zhong W, Chebolu S, Vaezi M, Alkam T. Broad-spectrum antiemetic potential of the Ltype calcium channel antagonist nifedipine and evidence for its additive antiemetic interaction with the $5-\mathrm{HT}(3)$ receptor antagonist palonosetron in the least shrew (Cryptotis parva). Eur J Pharmacol. 2014;722:2-12.

42. Marcelo KL, Means AR, York B. The Ca(2+)/Calmodulin/CaMKK2 Axis: Nature's Metabolic CaMshaft. Trends Endocrinol Metab. 2016;27:706-18. 
43. Lu KK, Armstrong SE, Ginnan R, Singer HA. Adhesion-dependent activation of CaMKII and regulation of ERK activation in vascular smooth muscle. Am J Physiol Cell Physiol. 2005;289:C1343-50.

44. Zhou J, Fan Y, Zhong J, Huang Z, Huang T, Lin S, et al. TAK1 mediates excessive autophagy via p38 and ERK in cisplatin-induced acute kidney injury. J Cell Mol Med. 2018;22:2908-21.

45. Bishr A, Sallam N, Nour El-Din M, Awad AS, Kenawy SA. Ambroxol attenuates cisplatin-induced hepatotoxicity and nephrotoxicity via inhibition of p-JNK/p-ERK. Can J Physiol Pharmacol. 2019;97:55-64.

46. Suetomi T, Willeford A, Brand CS, Cho Y, Ross RS, Miyamoto S, et al. Inflammation and NLRP3 Inflammasome Activation Initiated in Response to Pressure Overload by $\mathrm{Ca}(2+) / C a l m o d u l i n-$ Dependent Protein Kinase II delta Signaling in Cardiomyocytes Are Essential for Adverse Cardiac Remodeling. Circulation. 2018;138:2530-44.

47. Bisserier M, Berthouze-Duquesnes $M$, Breckler $M$, Tortosa F, Fazal L, de Regibus $A$, et al. Carabin protects against cardiac hypertrophy by blocking calcineurin, Ras, and $\mathrm{Ca} 2+$ /calmodulin-dependent protein kinase II signaling. Circulation. 2015;131:390-400; discussion

48. Al Rihani SB, Lan RS, Kaddoumi A. Granisetron Alleviates Alzheimer's Disease Pathology in TgSwDI Mice Through Calmodulin-Dependent Protein Kinase II/cAMP-Response Element Binding Protein Pathway. J Alzheimers Dis. 2019;72:1097-117.

49. Xu JY, Dai C, Shan JJ, Xie T, Xie HH, Wang MM, et al. Determination of the effect of Pinellia ternata (Thunb.) Breit. on nervous system development by proteomics. J Ethnopharmacol. 2018;213:221-9.

50. Lv C, Shi C, Li L, Wen X, Xian CJ. Chinese herbal medicines in the prevention and treatment of chemotherapy-induced nausea and vomiting. Curr Opin Support Palliat Care. 2018;12:174-80.

51. Bouron A, Chauvet S, Dryer S, Rosado JA. Second Messenger-Operated Calcium Entry Through TRPC6. Adv Exp Med Biol. 2016;898:201-49.

52. Schappe MS, Szteyn K, Stremska ME, Mendu SK, Downs TK, Seegren PV, et al. Chanzyme TRPM7 Mediates the $\mathrm{Ca}(2+)$ Influx Essential for Lipopolysaccharide-Induced Toll-Like Receptor 4 Endocytosis and Macrophage Activation. Immunity. 2018;48:59-74 e5.

53. Hirabayashi Y, Kwon S-K, Paek H, Pernice WM, Paul MA, Lee J, et al. ER-mitochondria tethering by PDZD8 regulates Ca dynamics in mammalian neurons. Science. 2017;358:623-30.

54. Yang J, Zhang R, Jiang X, Lv J, Li Y, Ye H, et al. Toll-like receptor 4-induced ryanodine receptor 2 oxidation and sarcoplasmic reticulum $\mathrm{Ca}(2+)$ leakage promote cardiac contractile dysfunction in sepsis. J Biol Chem. 2018;293:794-807.

\section{Figures}




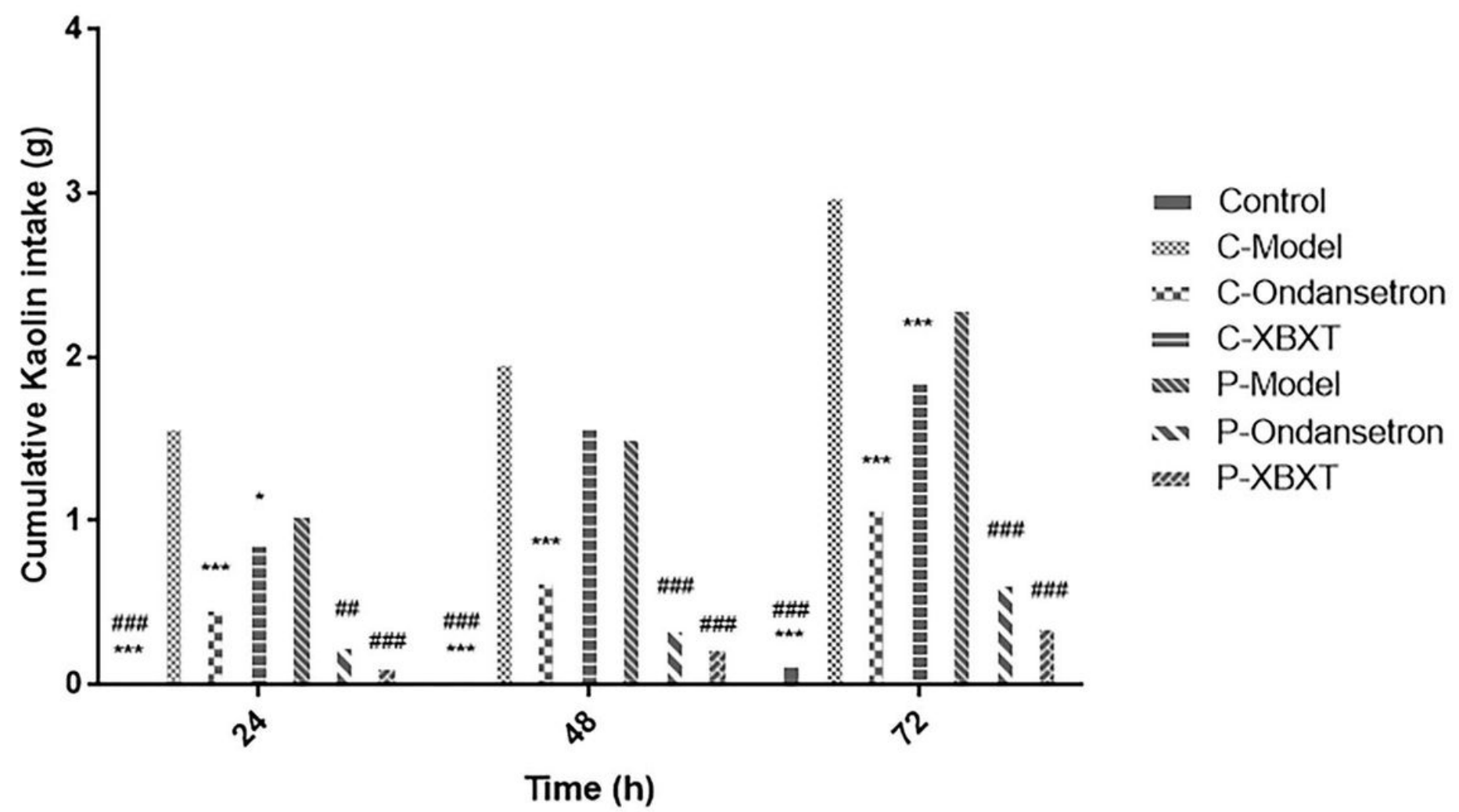

Figure 1

Effects of XBXT on kaolin consumption in 1-PBG induced rat pica model. Data represents mean \pm SEM.

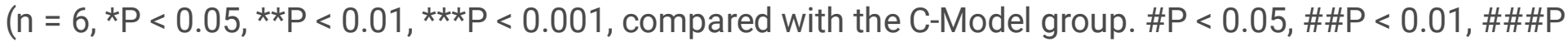
$<0.001$, compared with the P-Model group). Control, normal control group; C-Model, cisplatin model group; C-Ondansetron, ondansetron + cisplatin model group; C-XBXT, XBXT + cisplatin; P-Model, 1-PBG model group; P-Ondansetron, ondansetron + 1-PBG model group; P-XBXT, XBXT + 1-PBG model group. 


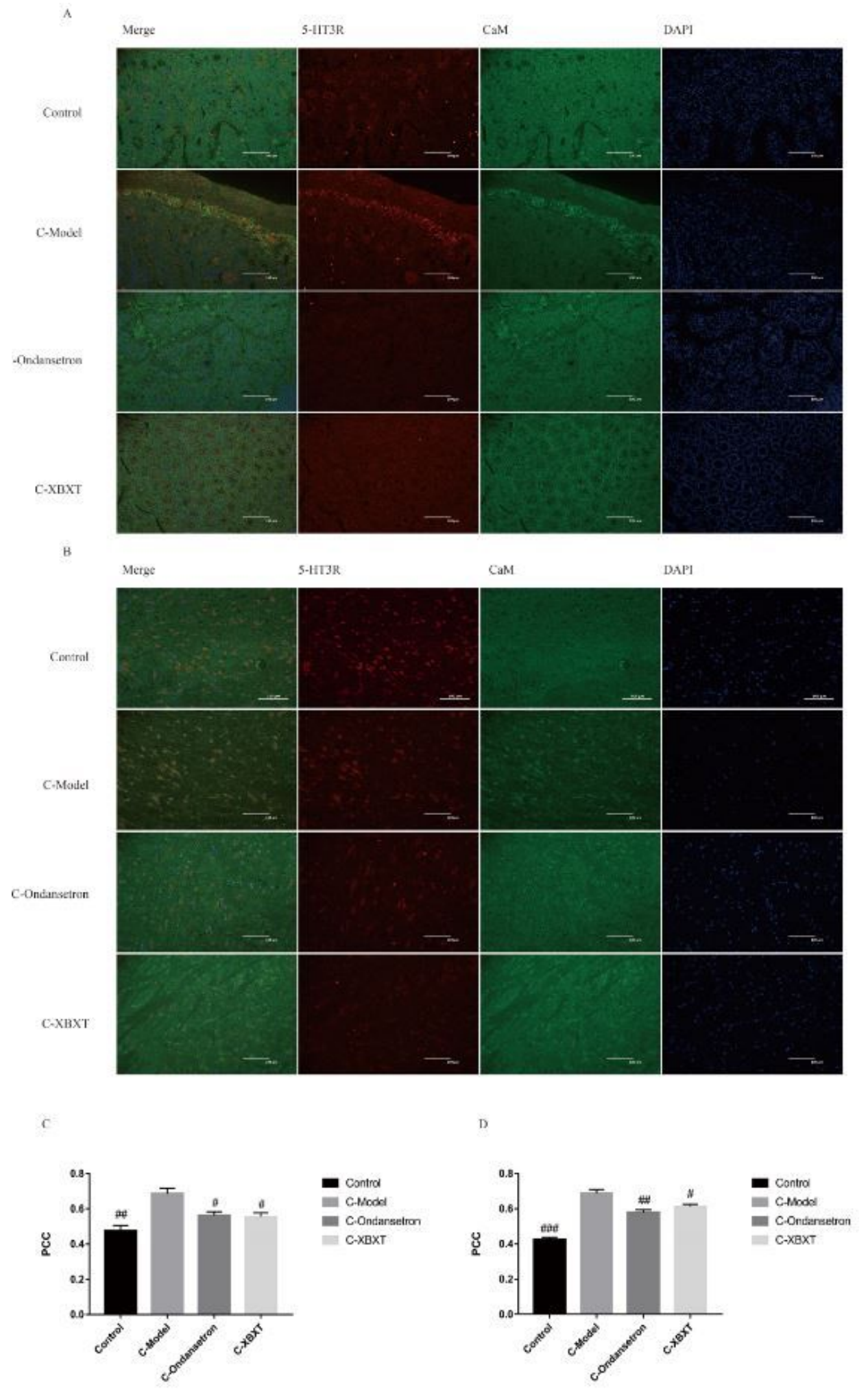

\section{Figure 2}

Expression and co-localization of 5-HT3R (red) and CaM (green) in cisplatin induced rat pica model. (A) The expression and co-localization of 5-HT3R and CaM in small intestine, (B) the expression and colocalization of 5-HT3R and CaM in brain. (C) Summarized data showing the co-localization efficiency (PCC, Pearson's correlation coefficient) of 5-HT3R with CaM in small intestine, (D) summarized data showing the co-localization efficiency (PCC, Pearson's correlation coefficient) of 5-HT3R with CaM in 
brain. Nuclei were stained with DAPI (blue). Photographs were observed under a fluorescence microscope at $200 \times$ magnification (scale bar $=100 \mu \mathrm{m})$. Data represents means \pm SEM. $(n=3, \# P<0.05, \# \# P<0.01$, \#\#\#P $<0.001$ vs C-Model group). Control, normal control group; C-Model, cisplatin model group; COndansetron, ondansetron + cisplatin model group; C-XBXT, XBXT + cisplatin; P-Model, 1-PBG model group; P-Ondansetron, ondansetron + 1-PBG model group; P-XBXT, XBXT + 1-PBG model group.
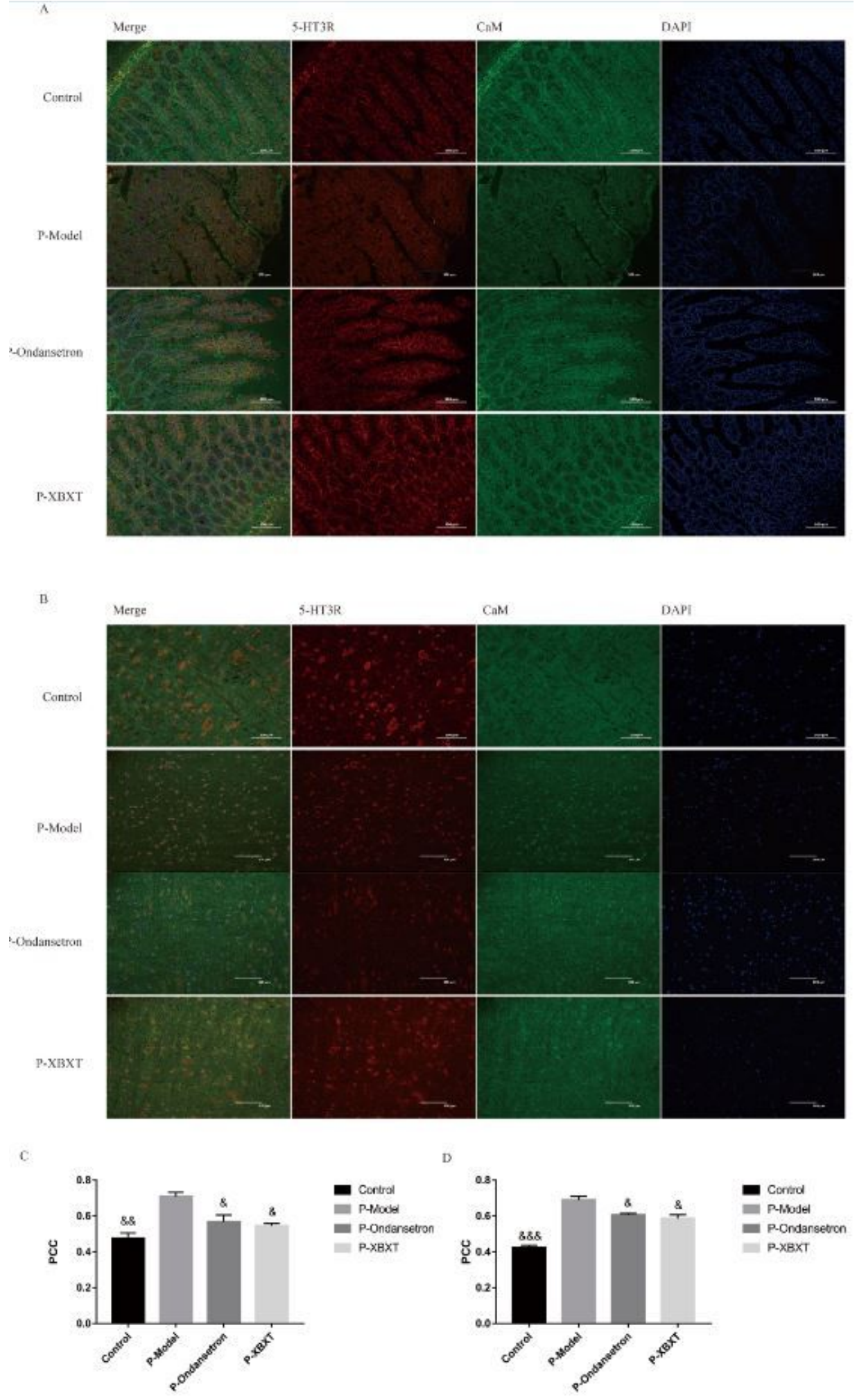

Figure 3 
Expression and co-localization of 5-HT3R (red) and CaM (green) in 1-PBG induced rat pica model. (A) The expression and co-localization of 5-HT3R and CaM in small intestine, (B) the expression and colocalization of 5-HT3R and CaM in brain. (C) Summarized data showing the co-localization efficiency (PCC, Pearson's correlation coefficient) of 5-HT3R with CaM in small intestine, (D) summarized data showing the co-localization efficiency (PCC, Pearson's correlation coefficient) of 5-HT3R with CaM in brain. Nuclei were stained with DAPI (blue). Photographs were observed under a fluorescence microscope at $200 \times$ magnification (scale bar $=100 \mu \mathrm{m})$. Data represents mean $\pm \operatorname{SEM}(n=3, \& P<0.05, \& \& P<0.01$, $\& \& \& \mathrm{P}<0.001$, compared with the P-Model group). Control, normal control group; C-Model, cisplatin model group; C-Ondansetron, ondansetron + cisplatin model group; C-XBXT, XBXT + cisplatin; P-Model, 1-PBG model group; P-Ondansetron, ondansetron + 1-PBG model group; P-XBXT, XBXT + 1-PBG model group.

\section{A}

Control C-Nodal c-Ondancotron c.xext

\section{CaMKII}

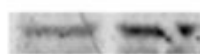

p-CaMKII

GAPDH

B
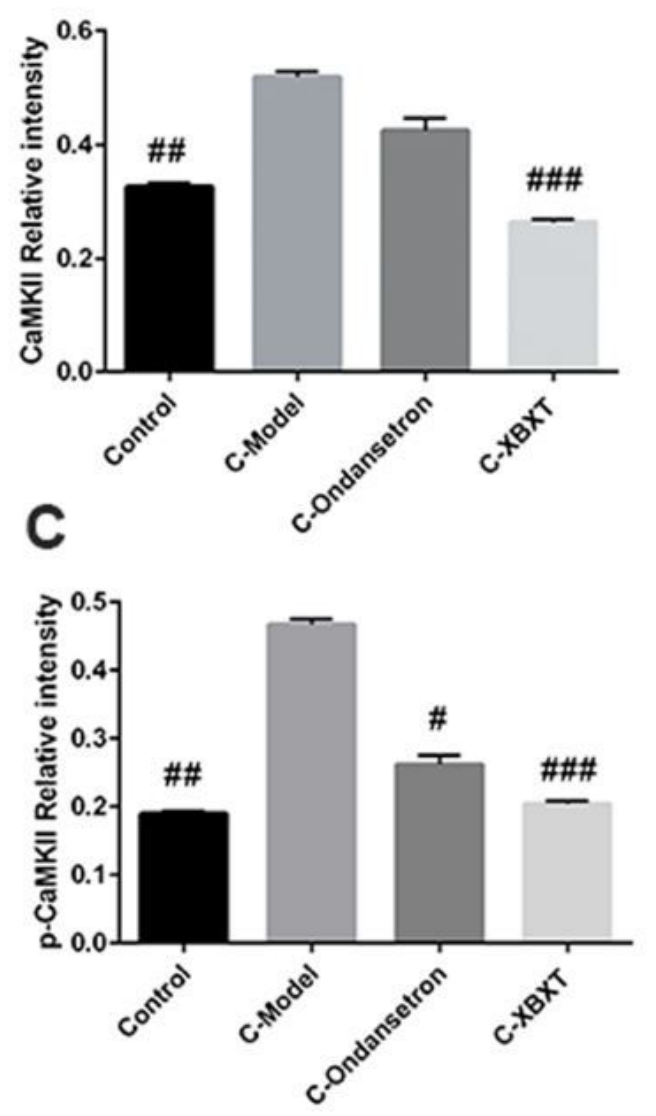

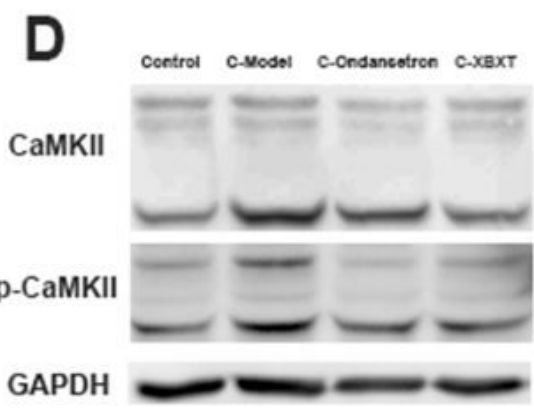

E

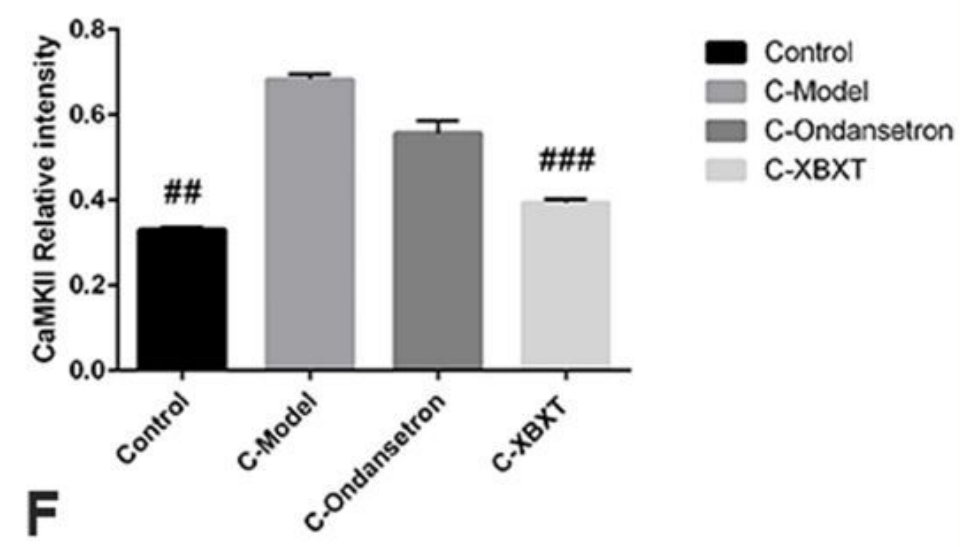

Control

C-Model

C-Ondansetron

C-XBXT
Control

C-Model

C-Ondansetron C.XBXT

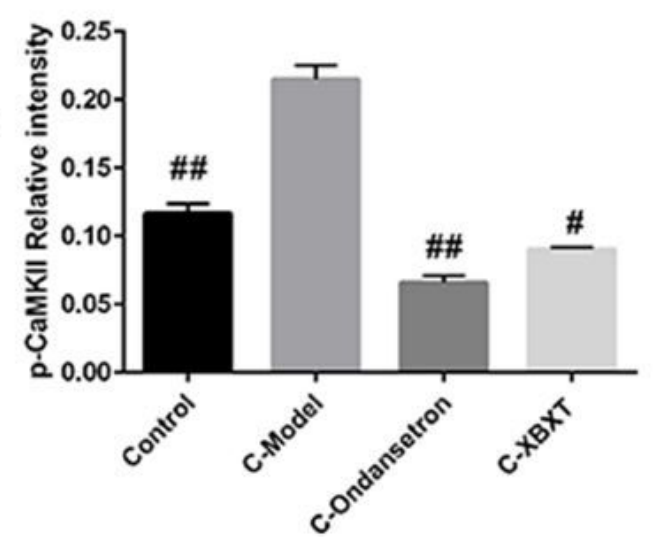

Figure 4 
Western Blot analysis of CaMKII and pCaMKII protein levels in cisplatin induced rat pica model. (ABC) The expression of CaMKII and pCaMKII protein levels in small intestine, (DEF) the expression of CaMKII and pCaMKII protein levels in brain. Data represents mean \pm SEM. $(n=3, \# P<0.05, \# \# P<0.01, \# \# \#<$ 0.001, compared with the C-Model group). XBXT, Xiao Ban Xia Tang; 1-PBG, 1-phenylbiguanide hydrochloride; Control, normal control group; C-Model, cisplatin model group; C-Ondansetron, ondansetron + cisplatin model group; C-XBXT, XBXT + cisplatin; P-Model, 1-PBG model group; P-Ondansetron, ondansetron + 1-PBG model group; P-XBXT, XBXT + 1-PBG model group.

\section{A}

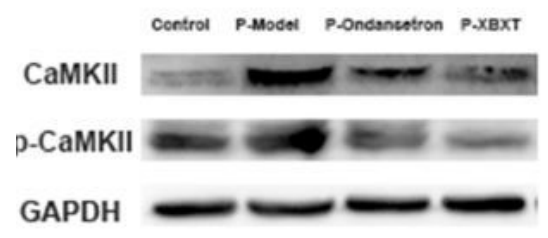

B
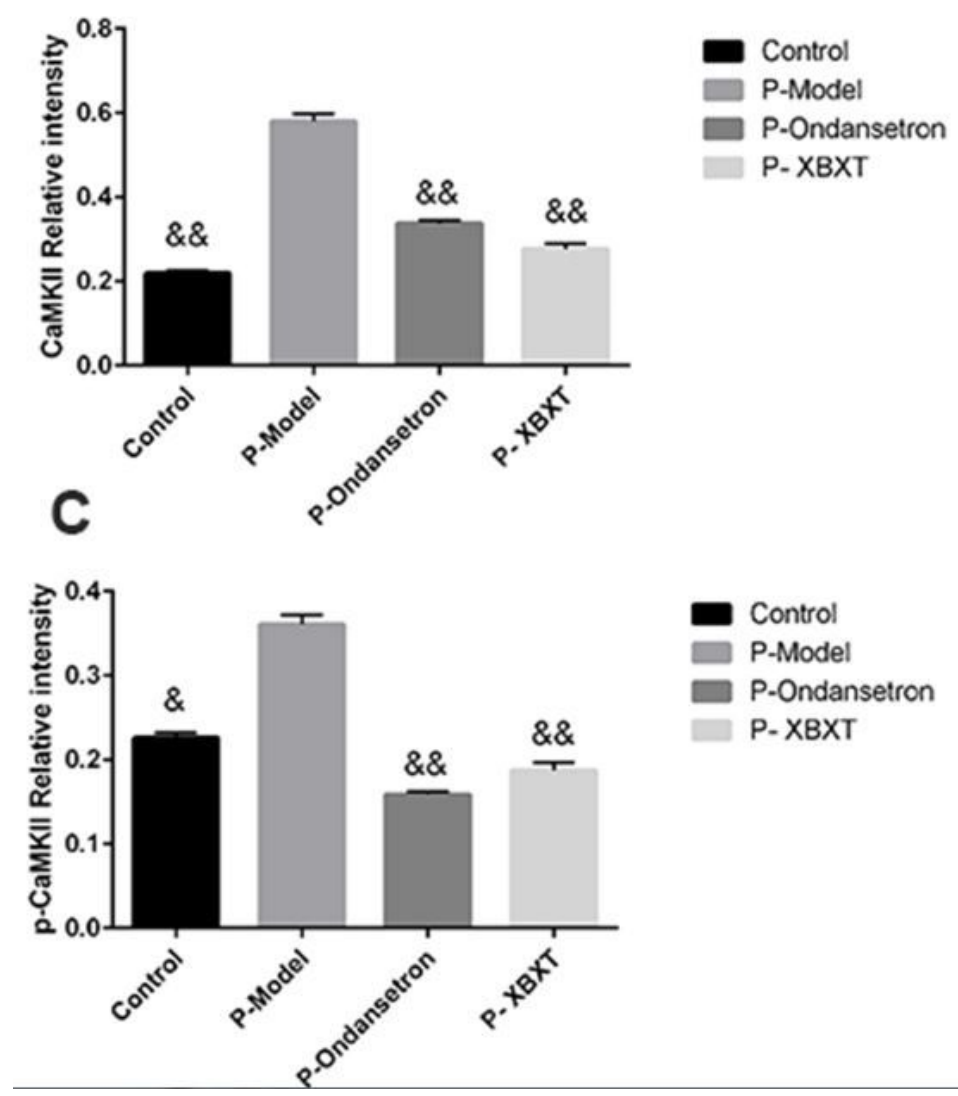

Control

P-Model

P-XBXT
P.Ondansetron

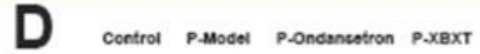

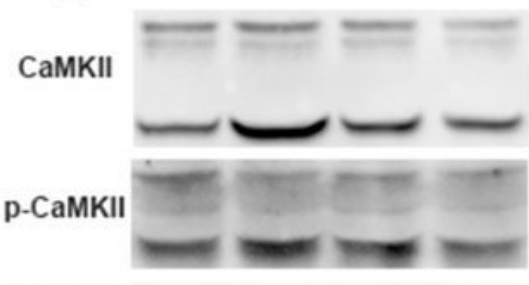

GAPDH
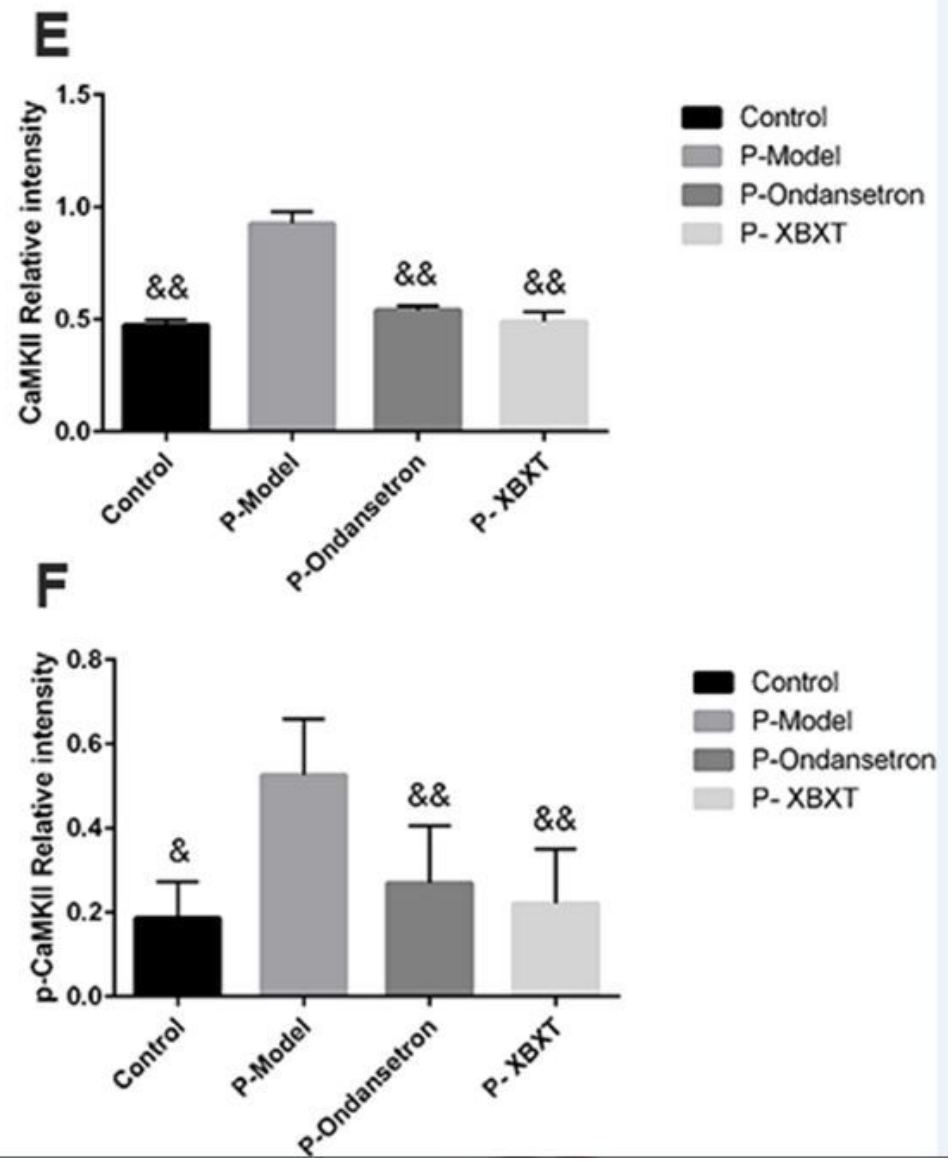

Figure 5

Western Blot analysis of CaMKII and pCaMKII protein levels in 1-PBG induced rat pica model. (ABC) The expression of CaMKII and pCaMKII protein levels in small intestine, (DEF) the expression of CaMKII and pCaMKII protein levels in brain. Data represents mean \pm SEM $(n=3, \& P<0.05, \& \& P<0.01, \& \& \& P<0.001$, compared with the P-Model group). XBXT, Xiao Ban Xia Tang; 1-PBG, 1-phenylbiguanide hydrochloride; 
Control, normal control group; C-Model, cisplatin model group; C-Ondansetron, ondansetron + cisplatin model group; C-XBXT, XBXT + cisplatin; P-Model, 1-PBG model group; P-Ondansetron, ondansetron + 1PBG model group; P-XBXT, XBXT + 1-PBG model group.

\section{A}

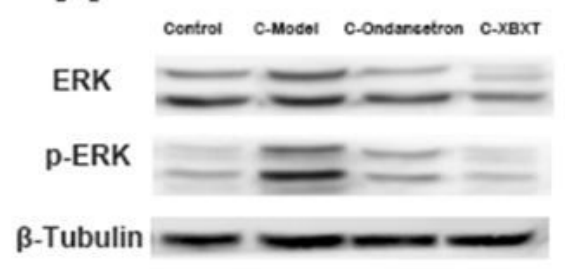

B
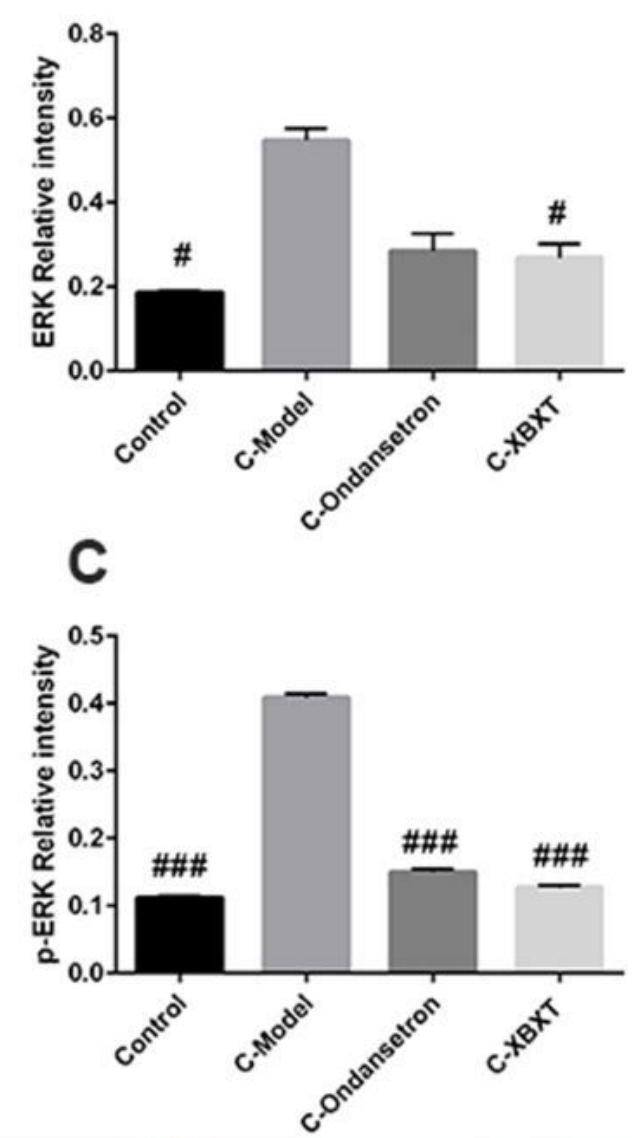

D

Control C-Model C-Ondancotron C.XBXX

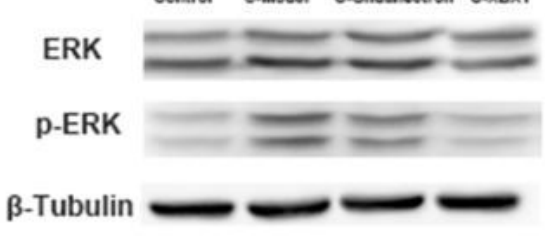

E

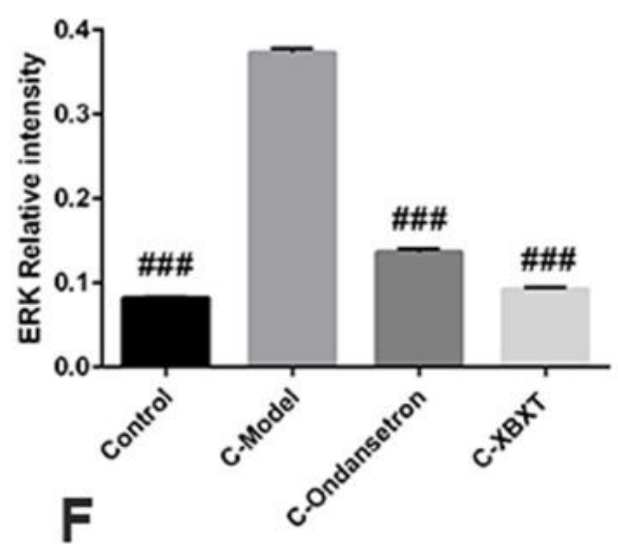

Control

C-Model

C-Ondansetron

C-XBXT

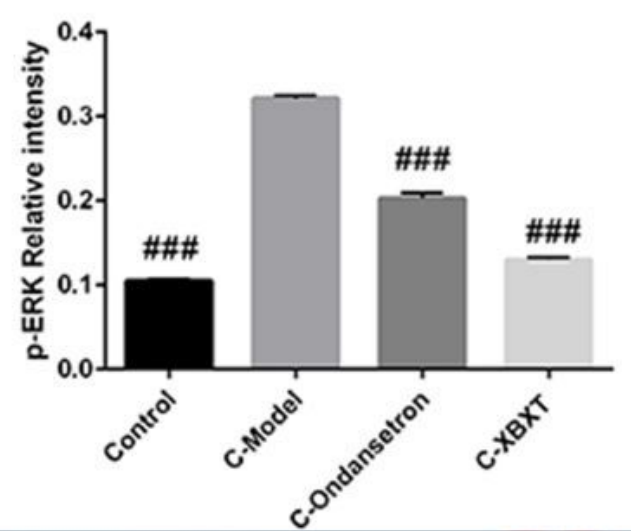

Control

C-Model

C-Ondansetron

C-XBXT

\section{Figure 6}

Western blot analysis of ERK1/2 and pERK1/2 protein levels in cisplatin induced rat pica model. (ABC) The expression of ERK $1 / 2$ and pERK1/2 protein levels in small intestine, (DEF) the expression of ERK1/2 and pERK1/2 protein levels in brain. Data represents mean \pm SEM $(n=3, \# P<0.05, \# \# P<0.01, \# \# \# P<$ 0.001, compared with the C-Model group). XBXT, Xiao Ban Xia Tang; 1-PBG, 1-phenylbiguanide hydrochloride; Control, normal control group; C-Model, cisplatin model group; C-Ondansetron, ondansetron + cisplatin model group; C-XBXT, XBXT + cisplatin; P-Model, 1-PBG model group; P-Ondansetron, ondansetron + 1-PBG model group; P-XBXT, XBXT + 1-PBG model group. 


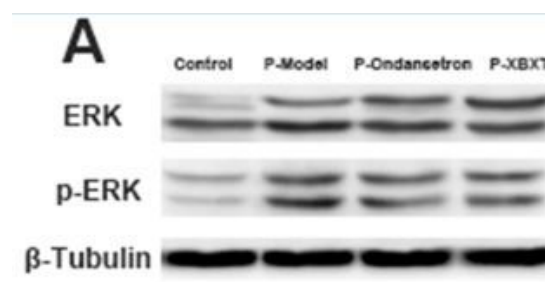

B
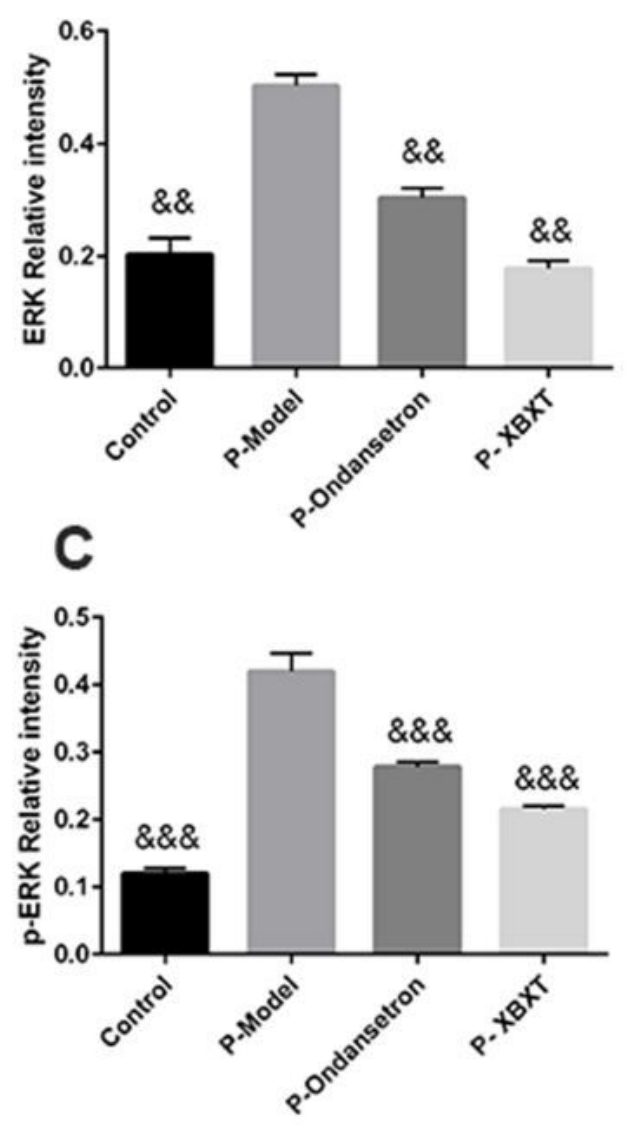

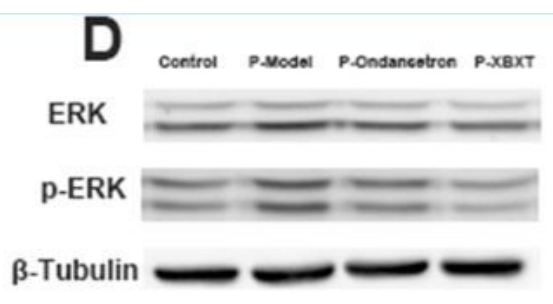

E

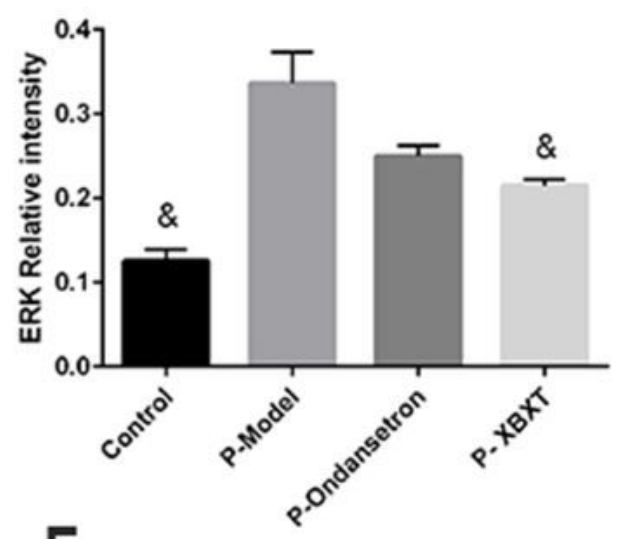

$\mathbf{F}$

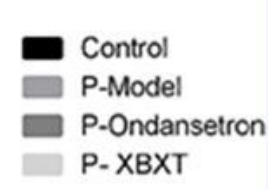

P-XBXT
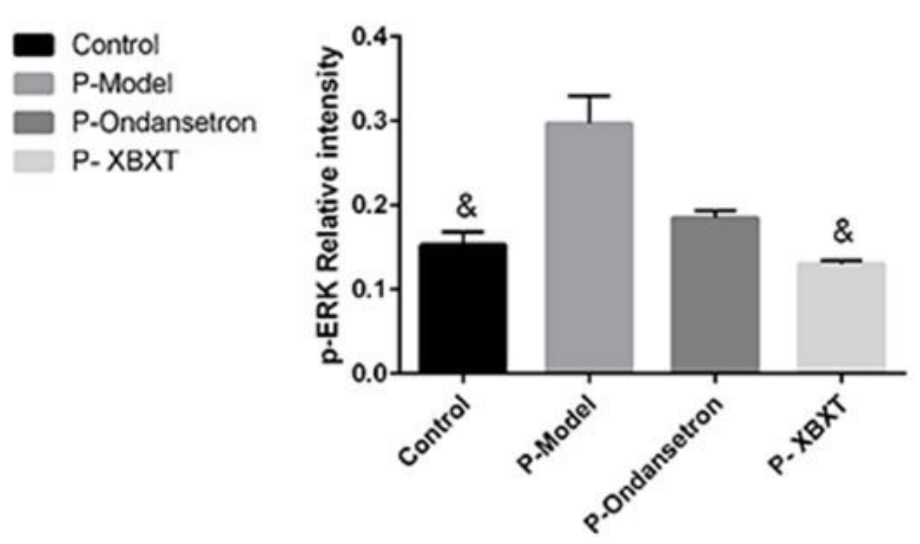

Control

P-Model

P-Ondansetron P- XBXT

\section{Figure 7}

Western blot analysis of ERK $1 / 2$ and pERK1/2 protein levels in 1-PBG induced rat pica model. (ABC) The expression of ERK $1 / 2$ and pERK $1 / 2$ protein levels in small intestine, (DEF) the expression of ERK $1 / 2$ and pERK1/2 protein levels in brain. Data represents mean \pm SEM. $(n=3, \& P<0.05, \& \& P<0.01, \& \& \& P<0.001$, compared with the P-Model group). XBXT, Xiao Ban Xia Tang; 1-PBG, 1-phenylbiguanide hydrochloride; Control, normal control group; C-Model, cisplatin model group; C-Ondansetron, ondansetron + cisplatin model group; C-XBXT, XBXT + cisplatin; P-Model, 1-PBG model group; P-Ondansetron, ondansetron + 1PBG model group; P-XBXT, XBXT + 1-PBG model group.

\section{Supplementary Files}

This is a list of supplementary files associated with this preprint. Click to download. 
- SupplementalFigure1.jpg

Page 22/22 